\title{
Breast cancer, metastasis, and the microenvironment: disabling the tumor cell-to- stroma communication network
}

\author{
Gerald J. Mizejewski \\ Wadsworth Center, New York State Department of Health, Albany, NY 12201-0509, USA.
}

Correspondence to: Dr. Gerald J. Mizejewski, Division of Translational Medicine, Molecular Diagnostics Laboratory, Wadsworth Center, New York State Department of Health, P.O. Box 509, Empire State Plaza, Albany, NY 12201-0509, USA.

E-mail: gerald.mizejewski@health.ny.gov

How to cite this article: Mizejewski GJ. Breast cancer, metastasis, and the microenvironment: disabling the tumor cell-to-stroma communication network. J Cancer Metastasis Treat 2019;5:35. http://dx.doi.org/10.20517/2394-4722.2018.70

Received: 30 Oct 2018 First Decision: 25 Jan 2019 Revised: 6 Feb 2019 Accepted: 7 Mar 2019 Published: 21 Apr 2019

Science Editor: William Schiemann Copy Editor: Cai-Hong Wang Production Editor: Huan-Liang Wu

\begin{abstract}
Breast cancer $(B C)$ is the leading cause of cancer-related deaths in women worldwide. However, the majority of cancer mortalities can be attributed to cancer cell metastasis to distal organs/tissues rather than the primary tumor mass itself. The microenvironment surrounding the main tumor mass, as well as its final migration destination, plays a crucial role in the survival, growth, proliferation, and progression of BC. Intercellular stromal cells and components of the microenvironment surrounding a tumor comprise a nurturing cubicle that provides a communication network of cross-talk and signaling between the tumor cells and the extracellular matrix (ECM) and interstitial cells. This network connection enables the tumor cells to engage in metastatic-associated activities such as cell adhesion, invasiveness, mobility, migration, cell shape change, cell-to-cell contact, and basement membrane degradation. An untapped therapeutic approach that might disable the communication network between cancer and stromal cells could possibly aid in providing this unmet need in treating metastatic disease. The intravenous administration of select protein-derived peptides to patients might have the potential to occupy, saturate, and block receptors and binding proteins at the interstitial/ECM communication interface with tumors.
\end{abstract}

Keywords: Alpha-fetoprotein, cancer, metastasis, breast, microenvironment, interstitium, extra-cellular matrix, stroma

\section{INTRODUCTION}

Breast cancer $(\mathrm{BC})$ and its metastasis are worldwide public health issues causing financial, economic, social, and personal lifestyle problems in addition to their high mortality rate. An increased metastatic potential in

cc) (i) The Author(s) 2019. Open Access This article is licensed under a Creative Commons Attribution 4.0 International License (https://creativecommons.org/licenses/by/4.0/), which permits unrestricted use sharing, adaptation, distribution and reproduction in any medium or format, for any purpose, even commercially, as long as you give appropriate credit to the original author(s) and the source, provide a link to the Creative Commons license, and indicate if changes were made. 
$\mathrm{BC}$ patients adds to their ultimate demise in both young and older women ${ }^{[1]}$. However, there exists an innate flaw in BC cell survival and metastasis regarding its dependence on the microenvironment that surrounds the malignant tumor ${ }^{[2]}$. This dependence presents a novel opportunity into an untapped therapeutic potential for BC patients with metastatic disease. The BC tumor mass maintains an intimate relationship with its microenvironment via a 2-way interchange of cross-talk and signaling communication cues between the two entities; this establishes a network-dependent connection ${ }^{[3]}$. When tumor growth outpaces its blood and nutrient supplies, cells detach from the primary mass seeking out new fertile "nesting" grounds. The process of cell detachment, migration, and dissemination is the hallmark of metastases with its widespread cell dispersion throughout the body; this results in an increased lethality more than the primary BC tumor itself. In 1889, Stephen Paget ${ }^{[4]}$ proposed a "seed and soil" hypothesis in which break-away tumor cells seek out tissue/organ sites which are beneficial to resume new tumor growth in sites resembling their original microenvironments. Thus, migratory tumor cells seek out secondary nurturing destinations in which tumor cells grow unabated in distal target organs such as liver, lungs, bone marrow, and brain.

The tumor cells themselves first undergo an epithelial-to-mesenchymal transition that transforms the cell's phenotypic identity to adopt a migratory and invasive behavior ${ }^{[5]}$. The dispersed migrating BC cells are attracted toward distal organ/tissue destinations under the influence of chemoattractant signals that determine their migratory gradient patterns and behavior. The chemotactic signals originate from a subfamily of secreted cytokines termed chemokines, most notably the CXCL12 ligand together with its cognate cell surface receptor, CXCR4. Such a 2-member complex is present on both tumor cells and stromal cells. Together, this chemokine/receptor complex forms an axis that can regulate cancer cell growth, proliferation, chemoresistance, angiogenesis, and metastasis ${ }^{[6]}$. Hence, both the directive and the objective of the present report are to address the cancer cell-to-microenvironment interaction as a potential therapeutic intervention strategy targeted toward disrupting the communication signaling network both at primary tumor and its metastatic sites.

\section{THE TUMOR MICRO-ENVIRONMENT COMPONENTS}

The micro-environment surrounding the primary tumor mass and that encompassing the metastatic destination site have similar shared communication networks. The tumor cell-to-microenvironment connection serves as a signaling bridge between tumor cells and interstitial stromal components which sponsor two-way communication systems. Such signaling activities include nutrient supply, angiogenesis, cell adhesion, migration, cell-to-cell contact, adherens cell junction maintenance, invasiveness, and basement membrane proteolysis ${ }^{[7]}$. Non-cellular constituents of the interstitium consists of multiple and diverse components such as: (1) metabolic by-products; (2) exosomes and microvesicles; (3) cell secreted and cell-surface proteins, co-factors and enzymes; (4) extracellular matrix components; (5) signaling molecules; and (6) endocrine and exocrine secretions such as cytokines. The non-malignant cell populations residing in the extracellular spaces and matrices consist of: (1) capillary and lymphatic cells of vessels and ducts; (2) extracellular matrix (ECM) cells; (3) stromal cells; (4) mesenchymal stem cells; (5) fibroblasts; (6) pericytes; (7) immune-associated cells (lymphocytes); (8) macrophages; (9) myofibroblasts; and (10) endothelial cells $^{[3,8,9]}$. Some of these constituent cells express and secrete various proteins involved in growth, cell movements, apoptosis, membrane proteolysis, and integrin and growth factor signaling. Thus, the cellular and non-cellular components of the instititual and ECM spaces represent an untapped source of potential molecular and cellular targets for cancer therapy. These will be addressed below.

\section{CELL SIGNALING IN THE MICROENVIRONMENT}

The tumor-to-microenvironment intracellular spaces offer a little-recognized cluster of molecular signaling targets with no place to hide. Hematologic and solid tumors are known to interact through microenvironments via cell surface chemokine receptors and their cognate ligands. As discussed above, the 
major components in the extracellular signaling arena are the chemokine receptor complexes present on both tumor and ECM cells, which activate diverse intracellular signaling transduction events as discussed above $^{[10]}$. Such intracellular signaling systems can activate a variety of pathways such as ERK1/2, p38, JAC/ STAT, SAPK/JNK, NF-кB, mTOR, PI3K-AKT, and BT-kinases ${ }^{[11]}$. Chemokine receptors, such as CXCR4 and CXCR7, represent members of the seven-transmembrane domain G-protein coupled receptor family that transmit intracellular activation of processes such as calcium flux, chemotaxis, transcription, cell cycle transition, and cell survival ${ }^{[13]}$. The disruption, blockage, or dysregulation of chemokine receptors and associated proteins could lead to aberrant off-target signaling and de-sensitization of the chemokine receptor transactivation apparatus.

At present, the increasing insight and appreciation of the functional role of the microenvironment to cancer growth and metastasis is prompting further research to more fully elucidate and investigate the tumor cellto-stoma cell dependency. The identification of metastasis-associated protein targets, both cell-bound and secreted, which occupy the extra-cellular matrix and spaces are key targets for disabling the communication lines between the tumor and the interstitium. The protein constituents which aid and abet this signaling complex display properties associated with processes such as cell adherence, cell-to-cell contact, invasion, immigration, matrix proteolysis, growth factor and receptor regulation, and ECM remodeling and restructuring. For example, a recent report has described the existence of a cancer cell-to-stromal macrophage EGF/CSF-1 paracrine signaling loop in the invasive spread of a primary rat mammary tumor [Figure 1]. The invasive response was inhibited by blocking the EGF and CSF receptors and/or macrophage function demonstrating that tumor migration invasiveness was dependent on the paracrine loop.

\section{PROTEIN CONSTITUENTS OF THE TUMOR MICRO-ENVIRONMENT}

The intrinsic pressure driving the metastatic process of tumor cells is the need for additional nurturing factors such as new blood vasculature and increased nutrients for the ever-expanding volume of the primary tumor cell mass. The disseminated tumor cells take advantage of the metastasis-associated proteins already residing in and on the cells of the ECM and interstitial spaces. These metastasis-associated proteins, so crucial for break-away tumor cells, are presented in the discourse listed below and in Table 1.

\section{Cell adherence and cell-to-cell contact family proteins}

Cell adherence and contact processes can be attributed to a gene superfamily termed the cadherins which consist of protocadherins, cadherins, desmocollins, desmogleins, contactins, and connexins ${ }^{[14]}$ [Table 1]. Such proteins function in cell adhesion to other cells, and to ECM constituents, and to formation of adherin junctions between cells. Cadherin family members display calcium $\left(\mathrm{Ca}^{2+}\right)$ binding repeat domains in their intrinsic polypeptide structure ${ }^{[15]}$. Different cadherin subfamily members can act in concert to join cells together in both homotypic and heterotypic types of attachments. Some family members (protocadherin Cad-13) serve to stabilize and maintain cell connections during oxidative stress, neural cell development, neurite outgrowth, cell signaling, invasion, and migration ${ }^{[16]}$. Other family members are involved in cell survival, potassium channel transmission, maintaining the microvasculature, KRAS signaling, and transmembrane activities. The PECAM, connexin, and contactin proteins play roles in gap junction maintenance, platelet adherence, and aged white blood cell removal and destruction ${ }^{[17]}$.

\section{ECM family proteins}

The ECM family of proteins include the integrins, zinc matrix metalloproteases (MMPs), A distingrin and metalloproteinase (ADAM) family, collagenases, gelatinases, and annexins ${ }^{[18]}$ [Table 1]. The MMPs are synthesized as nonactive precursor proteins which require proteolytic cleavage exposing catalytic hemopexin domains utilized for collagen degradation. The MMPs play key roles in development, metabolic disorders and diseases, immune and autoimmune disorders, and in cancer. In comparison, the ADAM family members function as transmembrane-anchored proteins resembling snake venom disintegrins which are 

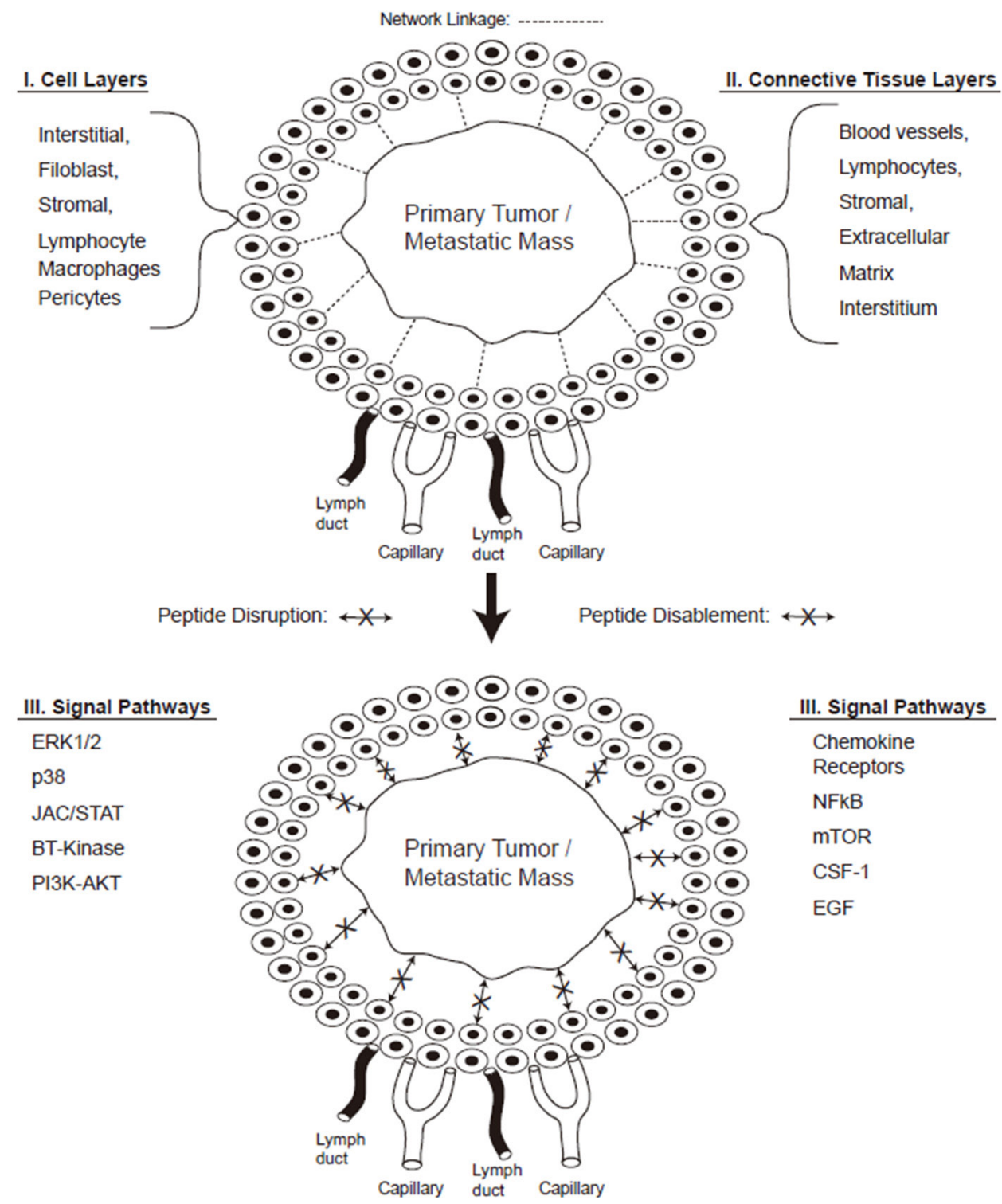

Figure 1. Peptide disruption of tumor to stroma communication. The peptide disruption of the tumor-to-stromal cell communication network is displayed together with the connective tissue layers, cell components, and signaling pathways. Note that the top half of the diagram displays the communication network connection indicated by the dashed lines (---) between tumor/stromal cells; while the bottom second half demonstrates the blocked linkage $(\leftarrow--X-\rightarrow)$ due to peptide disruption of tumor-to-stoma communication (see text for references and Ref.[45])

involved in cell mobility, migration, adhesion, platelet aggregation, and cell-to-cell contact; such processes occur during reproduction, neurogenesis, muscle development, and tumorigenesis ${ }^{[19]}$. The collagenases and gelatinases are family members involved in tissue remodeling, bone mineralization, reproduction, autoimmune diseases, inflammation, and cancer development ${ }^{[20]}$. The integrins are composed of alpha/beta chain proteins that participate in cell adhesion/contact and ECM-to-cell membrane inside-out signaling ${ }^{[21]}$. Finally, annexins are $\mathrm{Ca}^{2+}$ and phospholipid binding proteins that serve in blood coagulation processes ${ }^{[22]}$.

\section{The growth factor receptor family proteins}

The growth factor receptors associated with the tumor microenvironment and metastatic sites are largely G-coupled seven-transmembrane receptors containing kinase domains required for intracellular signaling and cross-talk between adjacent pathways ${ }^{[23]}$ [Table 1]. These receptors bind growth factors such as fibroblast 
Table 1. Selected metastasis-associated protein constituents of the tumor microenvironment are listed as four major functional groups. Such proteins are involved in cell activities such as adherence, mobility, growth, migration, invasiveness, angiogenesis, signaling, and proteolytic degradation

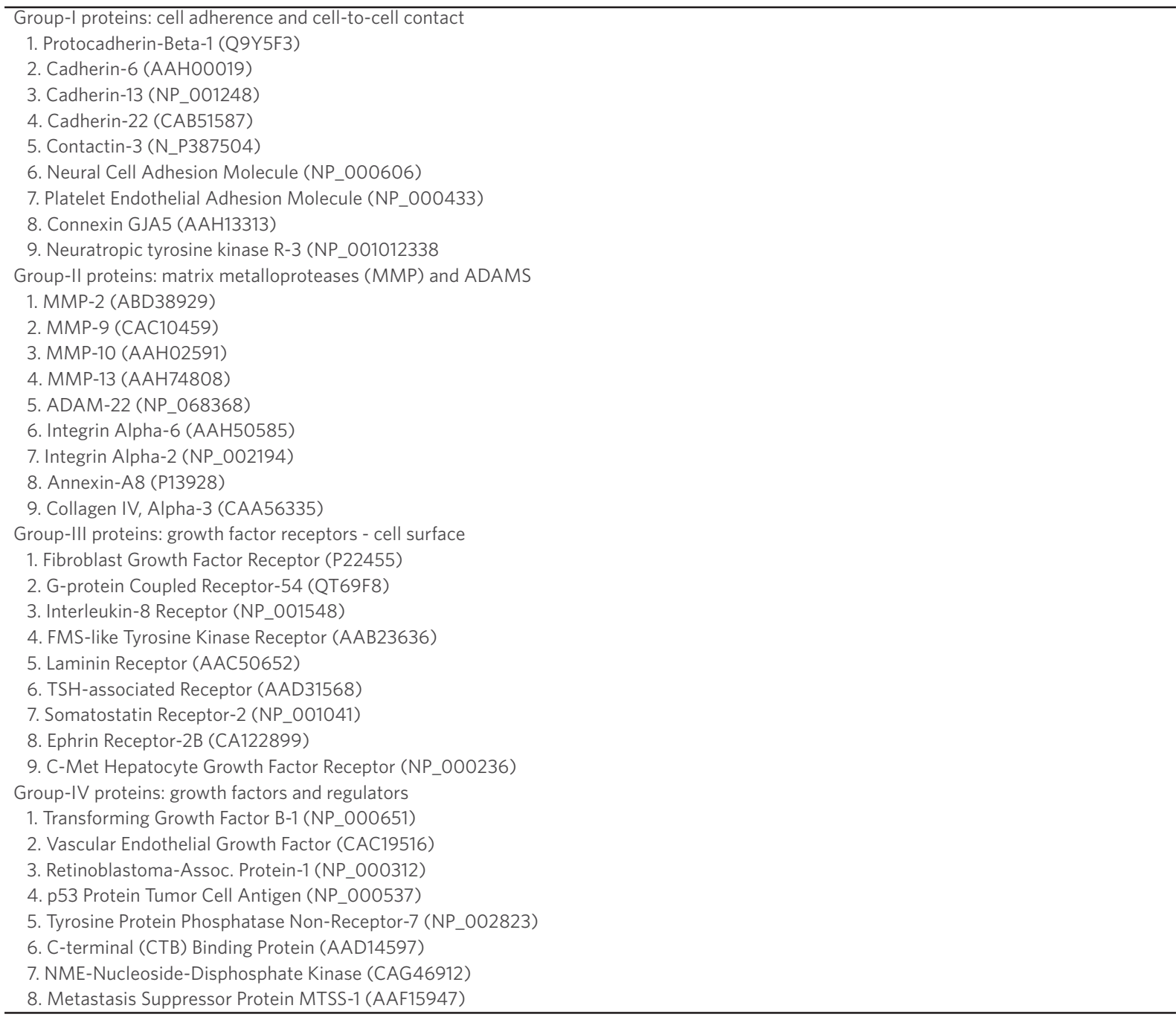

See Table 3 for Metastasis-associated functional activities, text, and Ref.[14-31]. Parenthesis indicates National Center for Bioinformatics $(\mathrm{NCBI})$ Accession number. ADAM: A disintegrin and metalloproteinase gene family

growth factor, laminin, somatostatin, ephrin, IL-8, and $\operatorname{KISSIR}^{[24]}$. The receptor-mediated activities encompass angiogenesis, mitogenesis, growth enhancement, differentiation, kinase function, cancer genesis and maintenance. These receptors can further activate, influence, and regulate cell cycle transitions, mitogenesis, cell motility, migration, and metastasis. Some receptors contain tyrosine kinase domains that enhance or influence growth in multiple tissues including the blood vasculature. The somatostatin receptors regulate the release of various hormone and secreted proteins, while the ephrin receptors are involved in tissue formation, cell migration and contact, stem cell differentiation, and cancer growth ${ }^{[25,26]}$. Finally, the G-coupled receptor-54 functions as a receptor for the KISS gene product, a cancer metastatic suppressor protein which when mutated, induces chemotaxis and invasion in numerous cancer cells. Thus, the metastasis-associated growth factor receptors are heavily involved in cell-to-ECM adhesion, invasion, migration, cancer growth and metastatic activities.

\section{Growth factor and regulator family members}

The microenvironment and metastasis-associated proteins encompass a wide range of growth factors and kinase enzymes that include transforming growth factor, vascular endothelial growth factor, MTSS1, p53 cell 
Table 2. Selected examples of naturally occurring protein-derived peptides (small proteins) are displayed together with their amino acid sequence numbers and protein of origin

\begin{tabular}{|c|c|c|c|}
\hline Name of peptide & $\begin{array}{l}\text { Number of amino } \\
\text { acids in sequence }\end{array}$ & Host protein of origin (pre-protein) & Peptide biological activity, function \\
\hline 1. Angiostatin & 184 & Plasminogen & Blocks blood vessel growth \\
\hline 2. Endostatin & 330 & Collagen Type XVIII & Angiogenesis inhibitor \\
\hline 3. Vasostatin & 180 & Calreticulin & Angiogenesis inhibitor \\
\hline 4. Constatin & 150 & Collagen Type IV & Inhibits endothelial cell growth \\
\hline 5. Tenacin & 220 & Fibronectin Repeat Domain & Anti-adhesion Function \\
\hline 6. Fragment of GHRH & 15 & $\mathrm{GHRH}$ & Stimulates Lipogenesis \\
\hline 7. Angiotension II & 8 & Angiotensinogen 22 Globulin & Increases Vasopressin Production \\
\hline 8. Bradykinin & 9 & Kininogen Precursor & Contracts Smooth Muscle \\
\hline 9. Oxytocin & 9 & Oxytocin Precursor & Uterine Contracting Hormone \\
\hline 10. Endothelin & 21 & Pre-Pro-Endothelial & Potent Vasoconstrictor \\
\hline 11. TRH & 3 & 242 Amino Acid Polypeptide Precursor & Governs Release of TSH \\
\hline 12. GIP* & 34 & $\begin{array}{l}\text { Alpha-fetoprotein polypeptide ( } 609 \\
\text { amino acids) }\end{array}$ & $\begin{array}{l}\text { Suppresses growth of hormone and non-hormone dependent } \\
\text { growth and proliferation (normal and cancer growth) }\end{array}$ \\
\hline \multicolumn{4}{|l|}{ GIP Sub-fragments: ${ }^{\star}$} \\
\hline (1) P149a & 12 & AFP AA\#464-475 & Inhibit platelet aggregation and blood factors \\
\hline (2) P149b & 14 & AFP AA\#476-488 & Blocks metastasis-assoc. proteins and cancer growth \\
\hline (3) P149c & 8 & AFP AA\#489-496 & Inhibits estrogen-dependent growth \\
\hline
\end{tabular}

Note that many peptides are derived from blood and extra-cellular matrix proteins. Naturally-occuring peptides can number in the hundreds of amino acids, while synthetic peptides are limited to 50 amino acids or less. *Synthetic peptides. AA: mino acid; AFP: alpha fetoprotein; GIP: growth inhibitory peptide; P149a: AAs; LSEDKLLACGEG (12 mer); P149b: AAs; AADIIIGHLCIRHE (14 mer); P149c: AAs; EMTPVNPG (also known as AFPep) (8-mer; both linear and cyclic). Data extracted from Ref.[33-38]. GHRH: growth hormone releasing hormone; TRH: thyroid releasing hormone; GIP: growth inhibitory peptide; TSH: thyrotrophin stimulating hormone

tumor antigen (phosphoprotein-53), tyrosine (tyr) protein-phosphate non-receptor type-7 protein, among others $^{[28,29]}$ [Table 1]. These proteins function in activities such as angiogenesis, tumorigenesis, metastasis, cancer proliferation, signal transduction, and cell cycle progression. Some of these proteins contain kinase enzyme domains which are contained in their polypeptide structure; other proteins act as regulators of cell cycle transition and tumor growth. The p53 cell antigen is a phospho-protein, which in the nonmutated state, normally function as tumor suppressors that protect the genome. The tyr (tyrosine) protein phosphatase non-receptor-7 is a signaling molecule involved in cell transformation, cell cycle transition, growth, and proliferation both in non-cancer and in malignant cells ${ }^{[30]}$. This latter protein further interacts with lymphokine-secretory cells and exhibits MAP kinase activity. Another family member of this group can phosphorylate the C-terminal end of the SRC family kinases, while the NDPK protein is involved with cell growth, proliferation, development, signal transduction, and G-protein coupled receptor activities ${ }^{[16]}$. Finally, the MTSS1 protein functions, in it's non-mutated state, as a metastasis suppressor protein that contains an actin binding (cytoskeletal) segment involved in cell migration ${ }^{[16]}$.

\section{Naturally-occurring protein-derived fragments}

There exists an extensive reserve of natural protein-derived peptide segments encrypted within the polypeptide structure of circulating blood proteins and ECM/interstitial cell-secreted proteins ${ }^{[31,32]}$. The proteome of both humans and other mammals contain precursors and preproteins that when cleaved by proteolysis, release peptide fragments with diverse biological activities. Although not widely mentioned, this containment fraction of active peptide fragments are derived from naturally-occurring sources such as blood proteins, growth factors, hormones, clotting factors, ECM proteins, and angiogenic factors. Such peptide fragments constitute segments from precursor derived proproteins or preproproteins which are produced following proteolytic enzyme degradation (i.e., trypsin); they can also be produced by cleavage in the laboratory using agents such as cyanogen bromide. Some of nature's most potent anti-angiogenic peptides are derived from abundant plasma proteins, growth factors, and ECM and stromal proteins ${ }^{[33,36]}$ [Table 2]. Such peptide fragments are garnering attention in the biomedical literature due to their functioning in signal transduction, receptor cross-talk, growth regulation, vasodilation/vasoconstriction, hormone release, blood clotting and inflammation ${ }^{[16]}$. Some peptide fragments can be cleaved from the amino-terminal 
Table 3. Selected cell adherence and cell-to-cell contact protein superfamily members are listed with their functional activities together with their third domain alpha-fetoprotein binding/interaction sites

\begin{tabular}{|c|c|c|c|}
\hline Selected Protein Name & Functional Activities & $\begin{array}{l}\text { AFP Amino Acid } \\
\text { Sequence Numbers }\end{array}$ & $\begin{array}{l}\text { AFP Amino Acid } \\
\text { Sequence }^{\star \star}\end{array}$ \\
\hline \multicolumn{4}{|c|}{ Cell adherence and cell-to-cell contact proteins } \\
\hline (1) Cadherin-6 & $\begin{array}{l}\text { Calcium dependent cell adhesions and } \\
\text { connections }\end{array}$ & $\begin{array}{l}\text { AA\#285-292 } \\
\text { AA\#500-507 }\end{array}$ & $\begin{array}{l}\text { FQTENPLE } \\
\text { CTSSYANR }\end{array}$ \\
\hline (2) Cadherin-22 & Cell adhesion, $\mathrm{K}^{+}$channel-associated & $\begin{array}{l}\text { AA\#481-488 } \\
\text { AA\#516-524 }\end{array}$ & $\begin{array}{l}\text { LGHLCIRH* }^{\star} \\
\text { VDETYVPP }\end{array}$ \\
\hline (3) Connexin GJA5 & Transmembrane GAP Junction Protein & $\begin{array}{l}\text { AA\#413-421 } \\
\text { AA\#529-537 }\end{array}$ & $\begin{array}{l}\text { KRSCGLFQ } \\
\text { DKFIFHKD }\end{array}$ \\
\hline \multicolumn{4}{|c|}{ Matrix metallo proteases and ADAM family proteins } \\
\hline (4) MMP-9 & Degrades ECM proteins, cell migration & $\begin{array}{l}\text { AA\#409-417 } \\
\text { AA\#444-452 }\end{array}$ & $\begin{array}{l}\text { GALAKRSC } \\
\text { SELMAITR }\end{array}$ \\
\hline (5) ADAM-22 & Cell-to-cell and matrix interaction & $\begin{array}{l}\text { AA\#429-437 } \\
\text { AA\#481-489 }\end{array}$ & $\begin{array}{l}\text { NAFLVAYT } \\
\text { IGHLCIRH }^{*}\end{array}$ \\
\hline (6) Integrin alpha-2 & $\begin{array}{l}\text { An interacting protein for laminin, collagen and } \\
\text { fibronectin }\end{array}$ & $\begin{array}{l}\text { AA\#433-441 } \\
\text { AA\#485-493 }\end{array}$ & $\begin{array}{l}\text { VAYTKKAP } \\
\text { CIRHEMTP* }\end{array}$ \\
\hline \multicolumn{4}{|l|}{ Growth factor receptors - cell surface } \\
\hline (7) Fibroblast growth factor receptor & Regulate cell growth, proliferation & $\begin{array}{l}\text { AA\#401-408 } \\
\text { AA\#477-485 }\end{array}$ & $\begin{array}{l}\text { LQKYIQES } \\
\text { ADIIIGHL* }\end{array}$ \\
\hline (8) Ephrin receptor & Receptor for cell migration and angiogenesis & $\begin{array}{l}\text { AA\#453-461 } \\
\text { AA\#477-485 }\end{array}$ & $\begin{array}{l}\text { KMAATAAT } \\
\text { ADIIIGHL* }\end{array}$ \\
\hline (9) G-protein coupled receptor-54 & Receptor for metastasis kiss peptide- 4 & $\begin{array}{l}\text { AA\#481-489 } \\
\text { AA\#500-507 }\end{array}$ & $\begin{array}{l}\text { IGHLCIRH* }^{\star} \\
\text { CTSSYANR }\end{array}$ \\
\hline \multicolumn{4}{|l|}{ Grow factors and regulators } \\
\hline $\begin{array}{l}\text { (10) Vascular endothelial grow } \\
\text { factor }\end{array}$ & $\begin{array}{l}\text { Stimulates vascular permeability for } \\
\text { angiogenesis }\end{array}$ & $\begin{array}{l}\text { AA\#477-485 } \\
\text { AA\#497-505 }\end{array}$ & $\begin{array}{l}\text { ADIIIGHL } \\
\text { QKLISKTR }\end{array}$ \\
\hline $\begin{array}{l}\text { (11) Metastasis suppressor protein } \\
\text { MTSS1 }\end{array}$ & Tumor metastasis; acts to bind actin & $\begin{array}{l}\text { AA\#425-433 } \\
\text { AA\#444-452 }\end{array}$ & $\begin{array}{l}\text { YYLQNAFL } \\
\text { SELMAITR }\end{array}$ \\
\hline $\begin{array}{l}\text { (12) Tyrosine phosphate } \\
\text { non-receptor type-7 }\end{array}$ & Regulates cell growth and cell cycle & $\begin{array}{l}\text { AA\#421-429 } \\
\text { AA\#477-485 }\end{array}$ & $\begin{array}{l}\text { KLGEYYLQ } \\
\text { ADIIIGHL }\end{array}$ \\
\hline
\end{tabular}

${ }^{\star \star}$ AFP amino acid sequence (single letter code); * growth inhibitory peptide (GIP) sequences. AFP: alpha-fetoprotein; ADAM: A disintegrin and metalloproteinase protein family; MMP: matrix metalloproteinases; Data extracted from Ref.[16,31,37-39]

or carboxy-terminal ends of various proteins, while others can be exposed following a conformational change in the proteins' tertiary structure. Such a conformational change in a protein can be induced by environmental events such as stress, shock, oxidative state changes, osmotic pressure, $\mathrm{pH}$, and high ligand concentrations ${ }^{[31,32]}$. Once identified in nature, single peptide fragments can be synthesized in the laboratory.

Examples of protein-derived fragments from the amino- or carboxy- ends of natural large proteins encompass a growing list of candidates. Such fragments include: angiotensin from angiotensinogen; endothelin from pre-pro-endothelin; bradykinin from kininogen, and others [Table 2]. Some examples of internal peptides encrypted within the chain of a protein include: Tenacin-C from fibronectin-III, angiostatin from plasmin, and endostatin from collagen-III [Table 2]. The chemically-synthesized peptides are usually restricted to less than 50 amino acids (AA) due to technical synthesis limitations, while naturally produced peptides can exceed 100 AAs. An example of a conformationally-exposed peptide segment from Table 2 is the growth-inhibitory peptide (GIP) derived from the full-length alpha-fetoprotein (AFP) molecule ${ }^{[37-40]}$. The GIP segment is uncovered on the AFP molecule following exposure of the protein to high concentrations of estrogens, fatty acids, and growth factors. The GIP-exposed form of AFP is a transitory (molten globular) form which can refold back to its natural tertiary structure following removal of the high ligand concentrations. The encrypted GIP segment on AFP is normally concealed within a hydrophobic cleft of the tertiary-folded AFP molecule. Moreover, GIP and its sub-fragments have been chemically synthesized, purified, and characterized in multiple assays of biological activities including anti-cancer growth and metastasis inhibition in both in vitro and in vivo models ${ }^{[37,38]}$. 
In the AFP derived GIP fragment example, a normal growth enhancing AFP molecule is converted to a growth inhibitory full-length protein capable of blocking normal and cancer growth and metastasis. Aside from GIP, other protein-derived peptide sites on the AFP third domain have since been identified and mapped; some such peptide segments have been found to bind and/or interact with other proteins such as metastasis-associated family members of the ECM, interstitial, and stromal proteins of tumor microenvironments ${ }^{[16]}$.

\section{Third-domain derived AFP peptide-interactions with ECM proteins}

As displayed in Table 2, the third domain of AFP provides an example of naturally occurring proteinderived peptides segments with biological activities of significance. The AFP third domain houses multiple peptide segments (8-10 or more amino acids) that have been identified by "in silico" prediction tools and molecular modeling; these were verified by in vitro cell-based assays and the AFP-derived peptides were found to bind various proteins ${ }^{[16,41,42]}$. Recent examples of confirmed protein-to-peptide binding interactions between AFP peptides and natural proteins include the scavenger receptor proteins, immune dendritic cells, mucin proteins, retinoic acid receptors, and metastasis-associated proteins in both cancer and nonmalignant models ${ }^{[42]}$. Logic would dictate that disruption and/or interference of cross-talk and signaling pathways between tumor cells and their surrounding proteins (both free and cell bound) located in the microenvironment might serve to hamper or obstruct this crucial linkage. As discussed above, the tumor microenvironment contains 4 or more protein families of metastasis-associated proteins relate to tumor cell detachment, adhesion, contact, and migration via the ECM. By use of the AFP receptor and protein binding third domain peptides as displayed in Table 3, it can be noted that such peptides might be capable of disabling and/or disrupting communication lines between the tumor primary mass and/or metastasis nesting sites. The identities of these potential protein-to-AFP peptide interaction sites with the metastasisassociated proteins from tumor micro-environments are addressed below.

\section{Interaction of metastasis-associated proteins with AFP-derived peptides}

It has previously reported that metastasis-associated proteins are capable of binding and/or interacting with AFP-derived peptides of the third domain ${ }^{[16,42]}$. In that report, members of the cell adhesion/contact protein family, such as cadherins, contactins and connexins were identified "in silico" to interact with AFP derived peptide sites on the amino-terminal half of domain-3, AA\#401-500. The same was true for the ECMassociated proteins of the MMP and ADAM family proteins being clustered from AA\# 409-480; moreover, these results showed interaction sites with AFP AA\# 504-558 in the carboxy end of domain-3. The third group of interacting proteins, the growth factor receptors, demonstrated two cluster interaction sites on AFP-3D; the first group at AA\#s 433-477 and the second grouping at AA\# 512-550. Finally, the last class of AFP interacting proteins, the growth factors and regulators, consisted of two distinct interaction regions; the first extending from AA\# 413-487, while the second encompassed sites at AFP AA\#S 508-522. It can be concluded from these data that metastasis-related proteins are potentially capable of interaction with various AFP peptide segments on both the 1st and 2 nd halves of the AFP domain- $3^{[16]}$.

\section{CONCLUSION}

It can be concluded from the above discourse that both naturally occurring protein-derived and synthetic peptides, ranging from 8-50 AA or larger, might be candidates capable of disabling tumor-tomicroenvironment communications. Such network connections are essential for supplying blood vascular and nutrient supplies from the ECM to the tumor, critical locations required for tumor survival and subsequent metastasis. The microenvironmental compartments surrounding tumors are required for successful cell detachment from the primary mass and taking advantage of migration and adhesion factors already present in the extracellular and stromal cell areas.

The present study further highlighted the many natural protein-derived peptides in human beings, whose activities involved cell adhesion, mobility, contact, angiogenesis, blood clotting, and tumorigenesis. In 
some instances, the derived peptide displayed an opposite action from its host protein such as angiogenic inhibition versus enhancement of new blood vessel growth. In another type of protein-derived peptide, the amino acid segment is not cleaved from the preproprotein, but rather exposed following a conformational change of the tertiary folded polypeptide. As an example, metabolic stresses of excessive ligand concentrations can temporarily convert the growth enhancing AFP molecule into a growth inhibitory protein. The transitory AFP molecule then refolds back to its tertiary form, and full length AFP once again displays the property of growth enhancement.

In the future, it might be feasible to administer short peptides to metastatic patients by injection, infusion, and osmotic pumps, or via sublingual routes to patients in early and/or late metastatic disease. Such peptides are also capable of down-regulating the expression of metastasis-associated proteins as previously described for $\mathrm{GIP}^{[44]}$. Peptides are short half-life molecules with good targeting properties, and adequate target binding (loading/off- loading) affinities ${ }^{[43]}$. Natural or synthesized peptides might potentially serve as treatment adducts in combination with next generation therapeutic cancer drugs. Peptide binding, occupation, downregulation, and saturation of ECM proteins in the interstitium may possibly serve to disable and sever the primary tumor and/or metastatic nesting sites from their ECM communication networks.

\section{DECLARATIONS}

\section{Acknowledgments}

The author extends his gratitude and thankfulness to Ms. Jennifer Wright in the typing and processing of this manuscript.

\section{Authors' contributions}

Mizejewski GJ solely contributed to the article.

\section{Availability of data and materials}

Not applicable.

\section{Financial support and sponsorship}

None.

\section{Conflicts of interest}

All authors declared that there are no conflicts of interest.

\section{Ethical approval and consent to participate}

Not applicable.

\section{Consent for publication}

Not applicable.

\section{Copyright}

(C) The Author(s) 2019.

\section{REFERENCES}

1. Siegel R, Ma J, Zou Z, Jemal A. Cancer statistics. CA Cancer J Clin 2014;64:9-29.

2. Tran-Thanh D, Done SJ. The role of stromal factors in breast tumorigenicity. Am J Pathol 2010;176:1072-74.

3. Amicone L, Marchetti A. Microenvironment and tumor cells: two targets for new molecular therapies of hepatocellular carcinoma. Transl Gastroenterol Hepatol 2018;3:24.

4. Liu Q, Zhang H, Jiang X, Qian C, Liu Z, et al. Factors involved in cancer metastasis: a better understanding to "seed and soil" hypothesis. 
Mol Cancer 2017;16:176.

5. Nieto MA, Huang RY, Jackson RA, Thiery JP. Emt: 2016. Cell 2016;166:21-45.

6. Mukherjee D, Zhao J. The role of chemokine receptor CXCR4 in breast cancer metastasis. Am J Cancer Res 2013;3:46-57.

7. Gupta GP, Massague J. Cancer metastasis: building a framework. Cell 2006;127:679-95.

8. Minciacchi VR, Freeman MR, Di Vizio D. Extracellular vesicles in cancer: exosomes, microvesicles and the emerging role of large oncosomes. Semin Cell Dev Biol 2015;40:41-51.

9. Peinado H, Lavotshkin S, Lyden D. The secreted factors responsible for pre-metastatic niche formation: old sayings and new thoughts. Semin Cancer Biol 2011;21:139-46.

10. Cavallaro S. CXCR4/CXCL12 in non-small-cell lung cancer metastasis to the brain. Int J Mol Sci 2013;14:1713-27.

11. Mizejewski GJ. Breast cancer, chemokines, and metastases: a search for decoy ligands of the CXCR4 receptor. J Neoplasms 2018;1:1-9.

12. Tran-Thanh D, Done SJ. The role of stromal factors in breast tumorigenicity. Am J Pathol 2010;176:1072-4.

13. Scala S. Molecular Pathways: Targeting the CXCR4-CXCL12 axis--untapped potential in the tumor microenvironment. Clin Cancer Res 2015;21:4278-85

14. Angst BD, Marcozzi C, Magee AI. The cadherin superfamily: diversity in form and function. J Cell Sci 2001;114:629-41.

15. Hulpiau P, van Roy F. Molecular evolution of the cadherin superfamily. Int J Biochem Cell Biol 2009;41:349-69.

16. Mizejewski GJ. The third domain ligand binding fragment of alpha-fetoprotein: detection of metastasis-associated molecular targets. Canc Therapy \& Oncol Intl J 2017;6:1-15.

17 Newman PJ, Newman DK. Signal transduction pathways mediated by PECAM-1: new roles for an old molecule in platelet and vascular cell biology. Arterioscler Thromb Vasc Biol 2003;23:953-64.

18. Nagase H, Woessner JF Jr. Matrix metalloproteinases. J Biol Chem 1999;274:21491-4.

19. Zhu P, Sun Y, Xu R, Sang Y, Zhao J, et al. The interaction between ADAM 22 and 14-3-3zeta: regulation of cell adhesion and spreading. Biochem Biophys Res Commun 2003;301:991-999.

20. Collier IE, Bruns GA, Goldberg GI, Gerhard DS. On the structure and chromosome location of the 72- and 92-kDa human type IV collagenase genes. Genomics 1991;9:429-34.

21. White DJ, Puranen S, Johnson MS, Heino J. The collagen receptor subfamily of the integrins. Int J Biochem Cell Biol 2004;36:1405-10.

22. Hauptmann R, Maurer-Fogy I, Krystek E, Bodo G, Andree H, et al. Vascular anticoagulant beta: a novel human Ca2+/phospholipid binding protein that inhibits coagulation and phospholipase A2 activity. Its molecular cloning, expression and comparison with VACalpha. Eur J Biochem 1989;185:63-71.

23. Ornitz DM, Xu J, Colvin JS, McEwen DG, MacArthur CA, et al. Receptor specificity of the fibroblast growth factor family. J Biol Chem 1996;271:15292-7.

24 Ohtaki T, Shintani Y, Honda S, Matsumoto H, Hori A, et al. Metastasis suppressor gene KiSS-1 encodes peptide ligand of a G-proteincoupled receptor. Nature 2001;411:613-7.

25. Lee J, Horuk R, Rice GC, Bennett GL, Camerato T, et al. Characterization of two high affinity human interleukin-8 receptors. J Biol Chem 1992;267:16283-7.

26. Yamda Y, Post SR, Wang K, Tager HS, Bell GI, et al. Cloning and functional characteristic of a family of human somatostatin receptors expressed in brain, gastrointestinal tract and kidney. J N Acad Sci (USA) 1992;89:251-5.

27. Ron D, Reich R, Chedid M, Lengel C, Cohen OE, et al. Fibroblast growth factor receptor 4 is a high affinity receptor for both acidic and basic fibroblast growth factor but not for keratinocyte growth factor. J Biol Chem 1993;268:5388-94.

28. Muller YA, Li B, Christinger HW, Wells JA, Cunningham BC, de Vos AM. Vascular endothelial growth factor: crystal structure and functional mapping of the kinase domain receptor binding site. Proc Natl Acad Sci USA 1997;94:7192-7.

29. Isobe M, Emanuel BS, Givol D, Oren M, Croce CM. Localization of gene for human p53 tumour antigen to band 17p13. Nature 1986;320:84-5.

30. Critton DA, Tortajada A, Stetson G, Peti W, Page R. Structural basis of substrate recognition by hematopoietic tyrosine phosphatase. Biochemistry 2008;47:13336-45.

31. Muehlemann M, Miller KD, Dauphinee M, Mizejewski GJ. Review of growth inhibitory peptide as a biotherapeutic agent for tumor growth, adhesion, and metastasis. Cancer Metastasis Rev 2005;24:441-467.

32. Mizejewski GJ. Cancer, circulating tumor cells, and metastasis: could protein-derived peptide fragments impede brain metastasis? J Cancer Metastasis Treat 2018;4:27.

33. Chiquet-Ehrismann R, Chiquet M. Tenascins: regulation and putative functions during pathological stress. J Pathol 2003;200:488-99.

34. Cao Y, Ji RW, Davidson D, Schaller J, Marti D, et al. Kringle domains of human angiostatin. Characterization of the anti-proliferative activity on endothelial cells. J Biol Chem 1996;271:29461-7.

35. Folkman J. Antiangiogenesis in cancer therapy--endostatin and its mechanisms of action. Exp Cell Res 2006;312:594-607.

36. Davenport AP, Hyndman KA, Dhaun N, Southan C, Kohan DE, et al. Endothelin. Pharmacol Rev 2016;68:357-418.

37. Mizejewski GJ, MacColl R. Alpha-fetoprotein growth inhibitory peptides: potential leads for cancer therapeutics Mol Cancer Ther 2003;2:1243-55

38. Mizejewski GJ, Butterstein G. Survey of functional activities of alpha-fetoprotein derived growth inhibitory peptides: review and prospects. Curr Protein Pept Sci 2006;7:73-100.

39. Mizejewski GJ, Muehlemann M, Dauphinee M. Update of alpha fetoprotein growth-inhibitory peptides as biotherapeutic agents for tumor growth and metastasis. Chemotherapy 2006;52:83-90.

40. Mizejewski GJ. The alpha-fetoprotein-derived growth inhibitory peptide 8-mer fragment: review of a novel anticancer agent. Cancer Biother Radiopharm 2007;22:73-98.

41. Mizejewski GJ. The alpha-fetoprotein (AFP) third domain: a search for AFP interaction sites of cell cycle proteins. Tumour Biol 2016;37:12697-711. 
42. Mizejewski GJ. Review of the putative cell-surface receptors for alpha-fetoprotein: identification of a candidate receptor protein family. Tumour Biol 2011;32:241-58.

43. Mizejewski GJ. Peptides as receptor ligand drugs and their relationship to G-coupled signal transduction. Expert Opin Investig Drugs 2001;10:1063-73.

44. Mizejewski GJ. Mechanism of cancer growth suppression of alpha-fetoprotein derived growth inhibitory peptides (GIP): comparison of GIP-34 versus GIP-8 (AFPep). Updates and Prospects. Cancers (Basel) 2011;3:2709-33.

45. Hernandez I, Smirnova T, Kedrin D, Wyckoff J, Zhu L, et al. The EGF/ESF-1 paracrine loop can be triggered by heregulin beta-1 and CXCL 12. Cancer Res 2009;69:3221-327. 